\title{
IDENTIDADES QUILOMBOLAS: ESTUDO DE CASO COM CRIANÇAS DA COMUNIDADE DE NOVA ESPERANÇA
}

\author{
Wesley Santos de Matos ${ }^{1}$ \\ Benedito Gonçalves Eugênio²
}

\begin{abstract}
RESUMO: Neste artigo, apresentamos algumas considerações de uma pesquisa do tipo estudo de caso, realizada com um grupo de crianças de uma escola quilombola no interior do estado da Bahia. Discutimos como elaboramos e realizamos a pesquisa, especificamente no que tange aos instrumentos que utilizamos para compreender as percepções das crianças sobre ser quilombola. Empregamos desenhos produzidos pelas crianças e entrevistas para a produção dos dados. As conclusões assinalam a importância dos desenhos para o processo de compreensão do reconhecimento construído pelas crianças pesquisadas.
\end{abstract}

Palavras-chave: Crianças quilombolas. Teoria do Reconhecimento. Desenhos.

\section{QUILOMBOL IDENTITIES: CASE STUDY WITH CHILDREN FROM THE COMMUNITY NOVA ESPERANÇA}

\begin{abstract}
In this article, we present some considerations of a case study research, carried out with a group of children from a quilombola school in the interior of the state of Bahia. We discussed how we designed and conducted the research, specifically regarding the instruments we use to understand children's perceptions of being quilombola. We use drawings produced by the children and interviews to produce the data. The conclusions indicate the importance of drawings for the process of understanding the recognition constructed by the children.
\end{abstract}

Keywords: Quilombola children. Theory of Recognition. Drawings.

\footnotetext{
${ }^{1}$ Mestre em Relações Étnicas e Contemporaneidade (UESB). Professor de História da Rede Estadual de Ensino da Bahia. E-mail: wesleyxdmattos@hotmail.com

${ }^{2}$ Doutor em Educação pela UNICAMP. Docente da Universidade Estadual do Sudoeste da BahiaCampus de Vitória da Conquista. E-mail: dodoeugenio@gmail.com
} 


\title{
IDENTIDAD QUILOMBOLA: ESTUDIO DE CASO CON NIÑOS DE LA COMUNIDAD DE NUEVA ESPERANZA
}

\begin{abstract}
RESUMEN: En este artículo, presentamos algunas consideraciones de una investigación de estudio de caso, realizada con un grupo de niños de una escuela quilombola en el interior del estado de Bahía. Discutimos cómo diseñamos y realizamos la investigación, específicamente con respecto a los instrumentos que utilizamos para comprender las percepciones de los niños de ser quilombola. Utilizamos dibujos producidos por los niños y entrevistas para producir los datos. Las conclusiones indican la importancia de los dibujos para el proceso de comprensión del reconocimiento construido por los niños.
\end{abstract}

Palabras clave: Niños quilombolas. Teoría del reconocimiento. Dibujos.

\section{Introdução}

O presente artigo apresenta os resultados de um projeto de pesquisa mais amplo sobre currículo e relações étnico-raciais em escolas quilombolas da Bahia, que conta com apoio do CNPq e é realizada em comunidades quilombolas de diferentes territórios de identidade do Estado da Bahia. Aqui discutimos o trabalho de campo realizado com as crianças de uma turma dos anos iniciais de uma escola quilombola localizada na comunidade Nova Esperança, comunidade quilombola rural situada no município de Wenceslau Guimarães-Bahia. Trazemos considerações metodológicas da pesquisa e buscamos mostrar como elaboramos e realizamos a pesquisa, especificamente no que tange aos instrumentos que utilizamos para compreender as percepções das crianças sobre ser quilombola.

Nova Esperança é uma comunidade quilombola certificada pela Fundação Cultural Palmares, em 2008. Em 2011 foi contemplada com uma escola padrão com recursos do Fundo Nacional de Desenvolvimento da Educação - FNDE. No entanto, 
cabe aqui ressaltar que já havia uma escola com turmas dos anos iniciais datada de 1993, cujo nome era Faustino José dos Santos, em homenagem a um dos filhos dos fundadores do lugar.

A Escola Quilombola Caminho da Boa Esperança oferece turmas da educação infantil ao ensino médio. A organização das turmas é assim configurada: 1 turma de Educação infantil - crianças de 4 e 5 anos de idade; 1 turma de 1/2ㅇaㅇ ano agrupados; 1 turma de 3으을 ano agrupados; 1 turma de 5으 ano (turma na qual foi desenvolvida a pesquisa de campo); 2 turmas de 6을 ano; 2 turmas de 70 ano; 1 turma de 8 ano,1 turma de 9o ano; 1 turma de Educação de Jovens e Adultos (EJA) 5aㅡㅁㅜ; 1 turma de EJA 7ạa /8 e 1turma de Ensino Médio com Intermediação Tecnológica (EMITEC) do 1ㅇao 3o ano do Ensino Médio. Da educação infantil até o 5ㅇa ano todas as turmas funcionam no período matutino; à tarde funcionam as turmas do Ensino Fundamental (anos finais) e no período noturno as turmas de EJA e EMITEC.

A Escola Quilombola Caminho da Boa Esperança conta com uma estrutura física constituída de oito salas de aula, uma biblioteca, uma secretaria que funciona em conjunto com a direção, uma sala de professores, uma cantina, quatro banheiros, sendo dois para uso dos estudantes e dois para os funcionários. Além dos espaços mencionados, a escola conta ainda com uma ampla área interna que é utilizada pelas crianças no intervalo em momentos de brincadeiras e descontração.

A pesquisa foi realizada em uma turma do 5 을 ano do ensino fundamental, composta por dezesseis estudantes. Devido aos preceitos de ética na pesquisa, as crianças participantes receberam nomes de pássaros da Mata Atlântica escolhidos em sua maioria por elas mesmas. Desse quantitativo, sete crianças são da comunidade quilombola Nova esperança: Curió, Bem-te-vi, Beija-flor, Chorão, Papa Capim, Águia e Pica-pau; quatro da comunidade São Lourenço (chamada de Muringa pelas crianças e 
moradores): Coleira, Tucano, Sete Cores e Coruja; uma do assentamento Chico Mendes: Arara; três do Riachão do Canto (região do entorno da comunidade): Queroquero, Andorinha e Guria; e uma do Daramãozinho (região do entorno da comunidade), Bacurau. Todas as crianças participantes da pesquisa são oriundas do campo e têm relação estreita com a terra. A pesquisa foi aprovada pelo Comitê de Ética em Pesquisa da Universidade Estadual do Sudoeste da Bahia sob o número CAAE 43806315.4.0000.0055.

\section{Método}

Para a produção dos dados, realizamos uma pesquisa qualitativa do tipo estudo de caso. Planejamos e realizamos oficinas de desenhos com as crianças com o intuito de capturar as realidades vivenciadas e construídas por elas. Além dos referenciais teóricos que advogam pelo uso dos desenhos, utilizamos também entrevistas semiestruturadas e registros nos diários de campo e todos estes instrumentos subsidiaram a compreensão do processo de construção de si pelas crianças quilombolas.

Empregamos os desenhos valendo-nos das possibilidades de interpretação que eles nos subsidiariam, num primeiro momento pensando em como as crianças se percebiam enquanto quilombolas e de que maneira eles se representariam em seus desenhos e num segundo momento e buscamos respostas acerca das suas relações com a comunidade.

A produção de desenhos também foi uma estratégia metodológica empregada por Pires (2007, p. 236). Segundo a autora

Ao desenhar sobre um tema proposto, as crianças colocam no papel o que Ihes é mais evidente. Nesse sentido, o desenho é um material de pesquisa interessante para captar justamente aquilo que primeiro vem à cabeça, aquilo que é mais óbvio para a criança. Porém, quando combinado com a 
observação participante, é que os dois instrumentos potencializam a sua utilidade. Os desenhos podem funcionar como um guia para a observação participante. Com os desenhos à mão, é possível direcionar o olhar para a realidade de acordo com os tópicos levantados pela população estudada.

Aquilo que a criança manifesta em suas falas e em seus desenhos não constitui apenas rabiscos ou grafismos típicos desta ou daquela etapa de desenvolvimento, como nos levam a crer as culturas de textos tidos por universais (GUSMÃO, 1999). Os desenhos documentam a realidade vivida e podem servir como fonte para reflexão e transformação dessa realidade (GOBBI; LEITE, 2009).

Analisamos os desenhos confeccionados pelas crianças sob a abordagem sóciohistórica, valendo-nos da contribuição da teoria do reconhecimento de Honneth. Gobbi e Leite (2009) nos ensinam que para analisar os desenhos infantis é fundamental pensarmos no contexto no qual os desenhos foram produzidos e suas condições de produção. Para as autoras

As Ciências Sociais não têm se dedicado ao estudo da infância e quando falamos em produções acadêmicas voltadas para os pequenos a coisa fica pior ainda. Quando falamos em desenhos infantis serem tratados como documentos históricos estamos dando a eles o peso e importância de tantos outros assim considerados. Historiadores e cientistas sociais não os percebem desta maneira, revelando um certo descaso com as concepções que as crianças têm do contexto histórico e social no qual estão inseridas, mostrando ainda não as perceber como atores e sujeitos da História (GOBBI; LEITE, 2009, p. 14).

A seguir, realizamos uma análise dos desenhos confeccionados pelas crianças buscando estabelecer uma relação com alguns autores que defendem o uso dos desenhos como técnica substancial nas pesquisas com crianças.

\section{Resultados e Discussão}

Há dois vieses pelos quais geralmente as pesquisas que utilizam os desenhos 
como recurso trilham, a saber: a maturacionista, que toma o desenho como recurso para definir em qual etapa a criança se encontra, concebendo-o como algo espontâneo e natural; e uma segunda que entende a criança como ator social que está inserido em uma teia de relações e como tal no processo de desenhar, podemos acessar em parte, a realidade vivida a partir do desenho produzido (NATIVIDADE; COUTINHO; ZANELLA, 2008). É a essa segunda perspectiva que nos filiamos.

Conforme apontam os trabalhos de Derdyk (1989), Ferreira (2001), Gobbi (2005) e Pereira (2005), os desenhos produzidos pelas crianças podem nos oferecer subsídios para trilhar um caminho privilegiado, no qual estão as ideias dos seus atores, vontades, emoções e de como elas veem e interpretam a realidade social. Como bem chamam a atenção Pedrine et al. (2010, p. 166), "o desenho vem sendo adotado como estratégia metodológica para a percepção da representação de emoções e concepções".

Leite (2004, s/p) também sinaliza que "Podemos perceber através da observação da criança a quem é oferecida a liberdade de criar, que no fazer artístico ela conta o quê e como sente, o quê e como pensa e o quê e como vê/percebe o mundo a sua volta. Dessa maneira, o uso dos desenhos se apresenta como uma possibilidade para o pesquisador apreender os significados e as significações construídas pelas crianças acerca da realidade de suas vidas cotidianas, compreendendo que elas retratam em suas obras seus percursos e suas experiências individuais ou coletivas, partindo do pressuposto de que o desenho e o que nele está representado não está dissociado da vida do seu autor.

Na perspectiva histórico-cultural, o desenho é pensado e percebido como um construto social, pois sendo o sujeito um ser social em sua origem, toda a sua produção é elaborada a partir das suas experiências sociais (NATIVIDADE; COUTINHO; ZANELLA, 2008). Nessa perspectiva, "As atividades simbólicas se consolidam por meio de 
impressões que a criança constrói sobre o seu universo cultural e histórico" (ARAÚJO; LACERDA, 2008, p. 444).

Conforme apontam Natividade, Coutinho e Zanella (2008), ler um desenho não é tarefa fácil, tampouco algo simples de se realizar, tendo em vista que os traços e signos ali contidos às vezes não falam por si mesmos. Sendo assim é preciso interpretálos. Essa talvez seja a função principal do pesquisador, pois desvelar e interpretar os desenhos possibilita a ele entender a realidade e as tessituras construídas pelas crianças em seus contextos de atuação. Para Natividade, Coutinho e Zanella (2008, p. 15)

[...] ao desenhar, ela objetiva a sua subjetividade, a realidade tal como significa, significação essa por sua vez construída a partir dos muitos outros com os quais convive/dialoga e dos sentidos que circulam nesses contextos. Sendo assim, compreende-se que o desenho expressa não apenas fantasia, mas também aquilo que a criança se apropria e o que ela significa da realidade.

Partindo de tais pressupostos, analisamos os desenhos confeccionados pelas crianças. Aliamos a análise dos desenhos aqui explorados às falas de algumas das crianças que foram entrevistadas, entendendo que, conforme apontam Natividade, Coutinho e Zanella (2008), a verbalização sobre o desenho elaborado por parte da criança é uma ferramenta importante para se compreender o contexto sócio-históricocultural em que ela vive e os sentidos atribuídos por ela a esse contexto.

As crianças pesquisadas se reconhecem etnicamente conforme o Quadro 1.

Quadro 1 - Como algumas crianças se reconhecem

\begin{tabular}{|c|c|}
\hline Nome & Resposta \\
\hline Cutia & Quilombola \\
\hline Beija-flor & Quilombola \\
\hline
\end{tabular}




\begin{tabular}{|c|c|}
\hline Guria & Quilombola \\
\hline Chorão & Quilombola \\
\hline Andorinha & Não quilombola \\
\hline Papa Capim & Quilombola \\
\hline Sete Cores & Quilombola \\
\hline Arara & Não quilombola \\
\hline Bem-te-vi & Quilombola \\
\hline Coruja & Não quilombola \\
\hline Tucano & Não quilombola \\
\hline
\end{tabular}

Quanto ao que pensam acerca da comunidade de Nova Esperança, as crianças assim se posicionaram, de acordo com o Quadro 2.

Quadro 2 - A comunidade de Nova Esperança segundo algumas crianças

\begin{tabular}{|c|c|}
\hline Nome & Resposta \\
\hline Cutia & $\begin{array}{c}\text { É muito legal, lá mora minha mãe, meu pai e eu brinco e } \\
\text { me divirto. }\end{array}$ \\
\hline Beija-flor & $\begin{array}{l}\text { Nova Esperança é um lugar em paz, legal é um povo alegre, } \\
\text { criativo e também eu gosto porque é tranquilo e no natal a gente } \\
\text { almoça no pé de árvore e todos brincam e faz o amigo secreto e } \\
\text { todo mundo é legal. }\end{array}$ \\
\hline Guria & Região boa e vivemos em felicidade. \\
\hline Chorão & Aqui é minha família, aqui o meu lugar. \\
\hline Andorinha & $\begin{array}{l}\text { A região onde eu moro é muito boa, eu gosto de lá e dos } \\
\text { meus amigos e da minha família e estou tendo mais amigos e eu sou } \\
\text { feliz com minha família, enfim gosto de lá. }\end{array}$ \\
\hline Papa Capim & $\begin{array}{l}\text { A comunidade é muito legal e tem um rio muito legal, } \\
\text { pessoas legais, a natureza e a comunidade. }\end{array}$ \\
\hline Sete Cores & Eu gosto muito de onde eu moro, é muito legal morar aqui. \\
\hline Arara & $\begin{array}{l}\text { A minha região é muito calma e perto da estrada, é } \\
\text { pequena só tem a casa da minha vovó e a minha, mas é muito }\end{array}$ \\
\hline
\end{tabular}




\begin{tabular}{|c|c|}
\hline & \begin{tabular}{c} 
divertida, juntos meus primos vamos todos brincar. \\
\hline Bem-te-vi
\end{tabular} \\
\hline $\begin{array}{c}\text { A comunidade é legal, tem uma praça para brincar e uma } \\
\text { escola grande que recebe alunos de todos os lugares. }\end{array}$ \\
\hline Coruja & $\begin{array}{r}\text { A região da Muringa é um lugar muito divertido, além de } \\
\text { ser movimentado, é muito alegre é assim que eu vivo lá. }\end{array}$ \\
\hline Tucano & $\begin{array}{r}\text { É tranquilo, tem muita mata também. É muito bom, tem } \\
\text { animais, tem campo de futebol e eu gosto muito daqui. }\end{array}$ \\
\hline
\end{tabular}

As crianças evidenciam, pela análise das falas presentes no Quadro 2 que as suas relações com a natureza são marcantes e que eles têm consciência que estão inseridos em uma comunidade quilombola. Outro fator importante que aparece é a relação com a família, que tem grande significado para elas. Essa relação de pertencimento ente família-comunidade aparece na fala de Chorão quando ele enfatiza que "aqui é minha família, aqui o meu lugar". Esse orgulho de ser quilombola, de fazer parte da comunidade mostra a consciência que a criança tem acerca do contexto que o envolve.

A comunidade, para as crianças, está associada a predicados positivos, quase sempre tendo relação estreita com a natureza que faz parte do cenário do lugar, como bem se reflete nas palavras Beija-flor: “Nova Esperança é um lugar em paz, legal é um povo alegre, criativo e também eu gosto porque é tranquilo e no natal a gente almoça no pé de árvore e todos brincam e faz o amigo secreto e todo mundo é legal". Assim como asseguram Gobbi e Leite (2009), em suas análises acerca dos desenhos das crianças, elas têm o poder de representar o contexto em que estão inseridas, bem como suas realidades sociais. Em oficina realizada com as crianças com a temática "O lugar que eu mais gosto na comunidade", alguns desenhos evidenciaram essas questões, conforme vemos na Figura 1. 


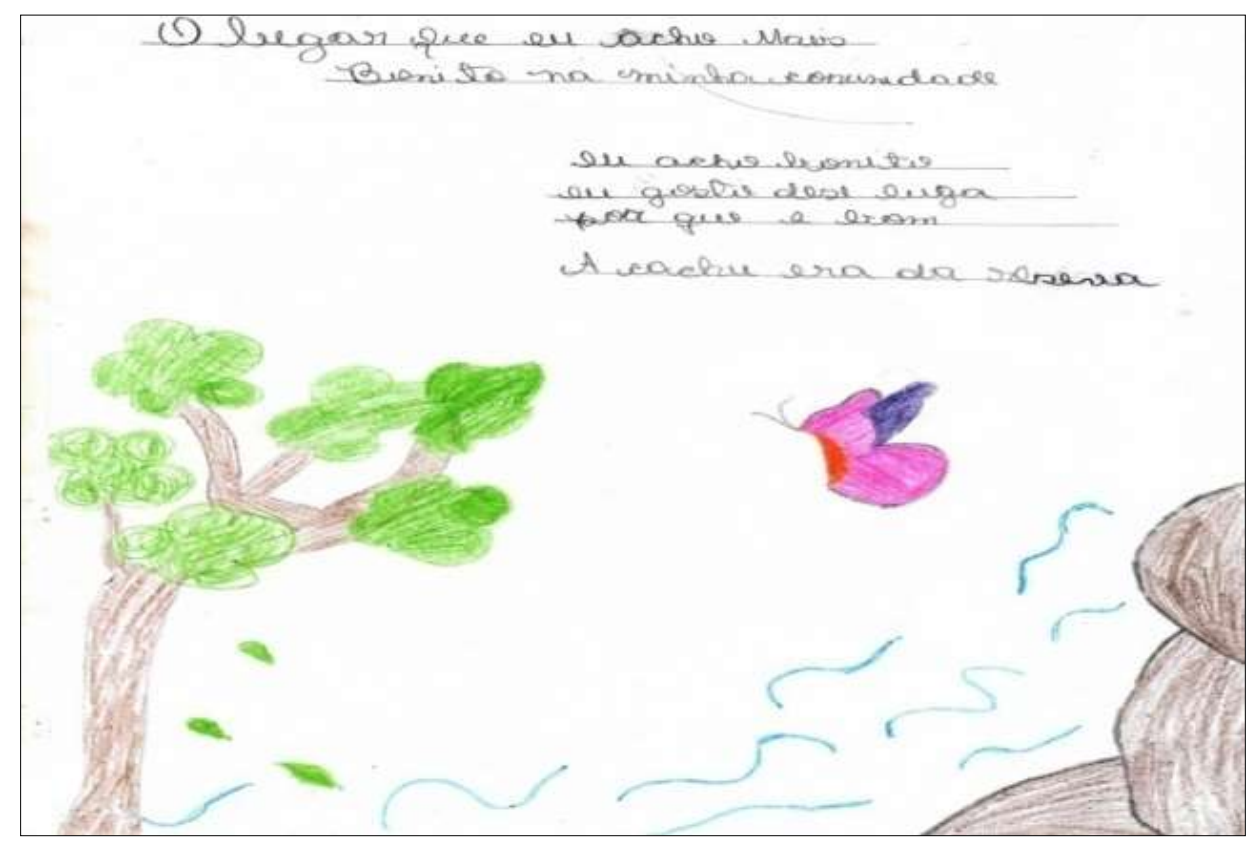

Figura 1 - Desenho de Beija-flor - 11 anos.

Essa relação positiva construída entre as crianças e o meio ambiente no qual a comunidade está imersa é confirmada pelo discurso de Papa Capim ao apontar que "A comunidade é muito legal e tem um rio muito legal, pessoas legais, a natureza e a comunidade". Nessa perspectiva, natureza e comunidade estão imbricados numa relação de interdependência, em que as belezas naturais são enfatizadas pelas crianças para elevar o valor simbólico do lugar ao qual eles fazem parte. Essa correspondência entre a comunidade e o contexto é refletida no desenho de Canário, na Figura 2. Além da cachoeira, ele elenca outros elementos da natureza que estão presentes na comunidade.

A importância valorativa que as crianças têm em relação à comunidade se evidenciam muito mais pelo fator rural e camponês que pela condição do ser quilombola do lugar. Esse detalhe aparece nos desenhos em segundo plano, um tanto de forma implícita, pois eles apontam para os lugares que mais acham bonitos sem, no 
entanto, fazer referência ao ser quilombola.

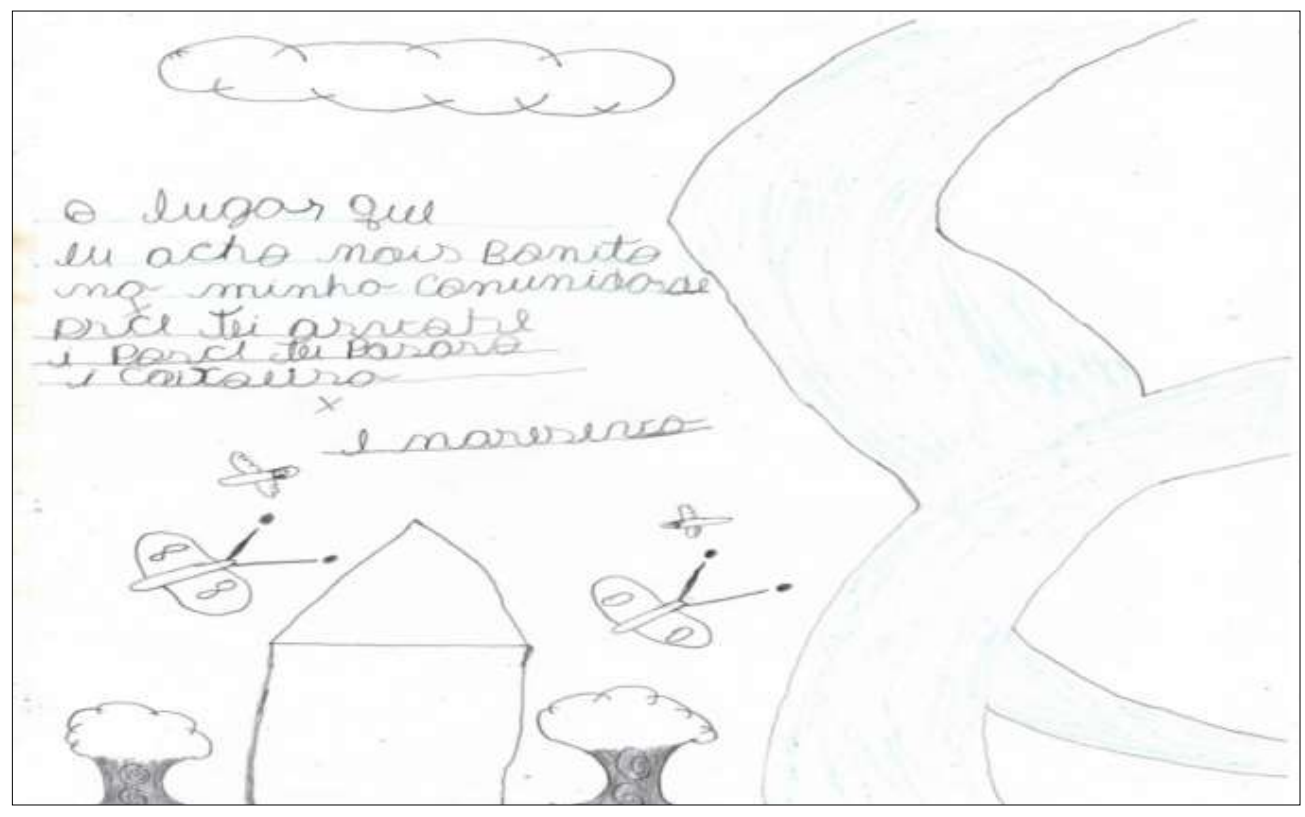

Figura 2 - Desenho de Canário - 10 anos.

Em conversa contida no diário de campo de no 16 , as crianças falam o que significa a cachoeira para eles.

Reservamos um momento para falar informalmente sobre aquele lugar e com todo cuidado perguntei para eles qual o significado tinha aquele lugar para eles e, quase que em coro parecendo que tinham combinado responderam: "esse lugar para nós é felicidade, na comunidade não temos muita coisa, então quando a gente vem aqui, principalmente no verão é motivo de felicidade" (Diário de campo no 16).

A cachoeira é, para as crianças, um lugar de sociabilidades. A relação entre as crianças e esse lugar é tão singular que aparece também no desenho e na fala de Papa Capim, Figura 3.

O estudante, com todo cuidado, demonstra no seu desenho a importância que esse lugar tem para a comunidade como um todo, evidenciada em sua preocupação 
com a preservação da cachoeira.

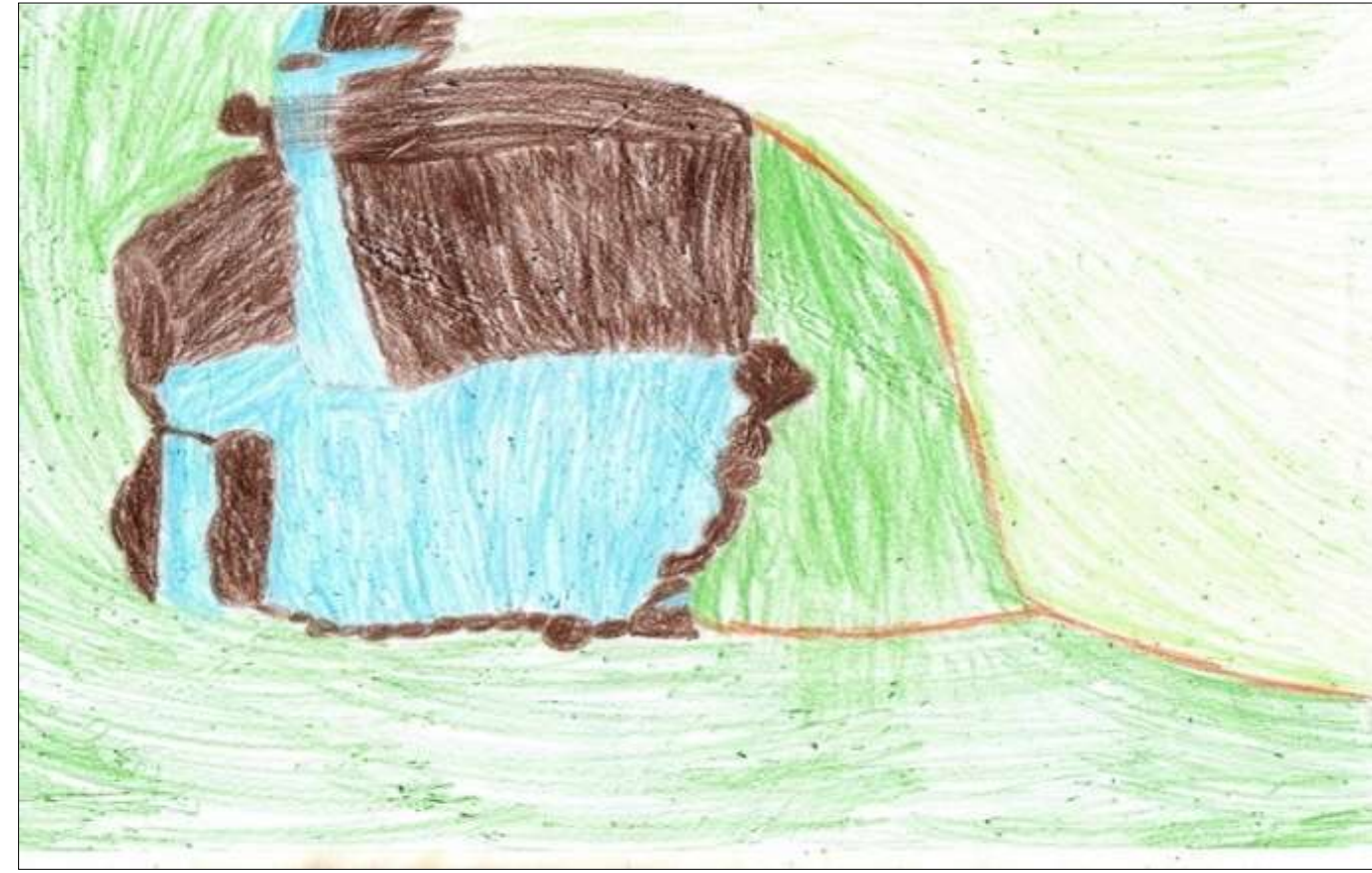

Figura 3 - Desenho de Papa Capim - 13 anos.

O amor e o cuidado para com a cachoeira se expressam pela tonalidade viva das cores usadas por Papa Capim. Registramos a preocupação dessa criança com a degradação ambiental que a cachoeira vem passando.

Papa Capim me fala que o poço ultimamente tá muito sujo, o povo vai tomar banho lá e não recolhe o lixo, deixa tudo dentro da água, realmente percebi que no entorno do poço tinha muita embalagem plástica de consumo humano e alguns locais onde as pessoas faziam fogueiras (Diário de campo, $\left.n^{\circ} 16\right)$.

Além desse lugar, as crianças têm outra referência que é motivo de felicidade. Quando se fala de brincadeiras e diversão, o campo de futebol é quase que unanimidade entre eles. Essa relação entre os estudantes e o futebol fica evidenciada no desenho de Sete Cor, na Figura 4, quando este retrata em seu desenho esse lugar como sendo o seu lugar favorito na comunidade. 


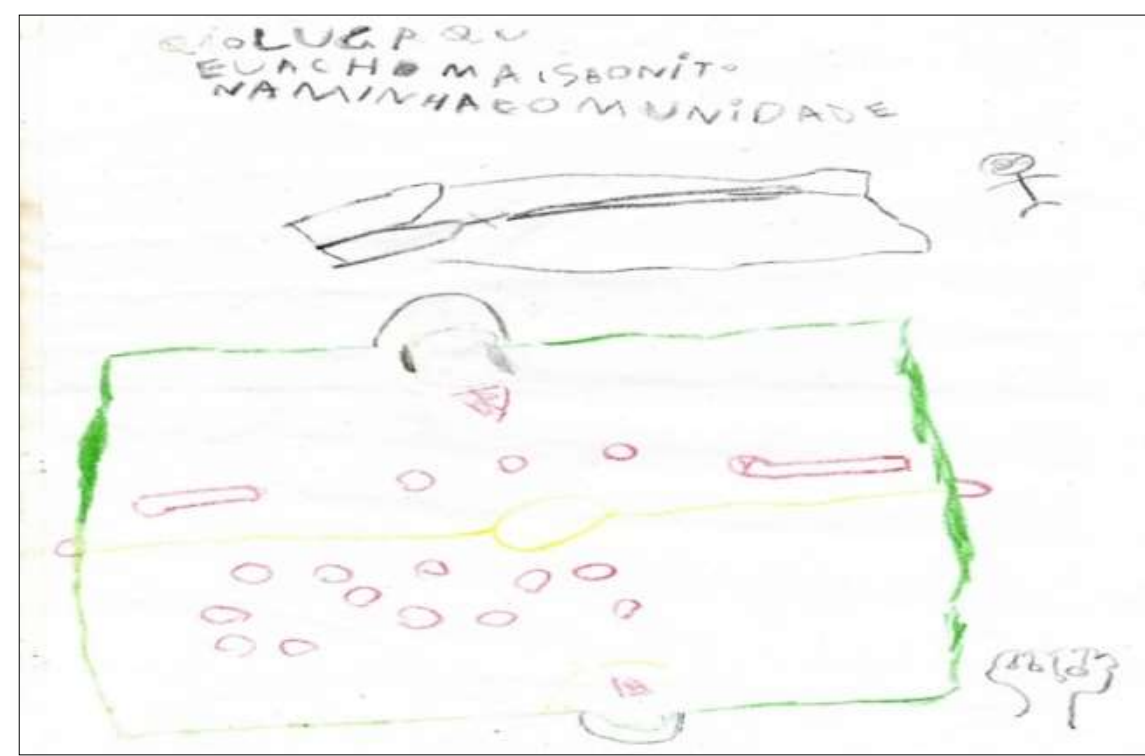

Figura 4 - Desenho de Sete Cor - 11 anos.

A relação afetuosa com o futebol faz do seu espaço um dos lugares na comunidade que tem uma atenção diferenciada por parte das crianças, tendo em vista que segundo eles há poucos espaços para o lazer.

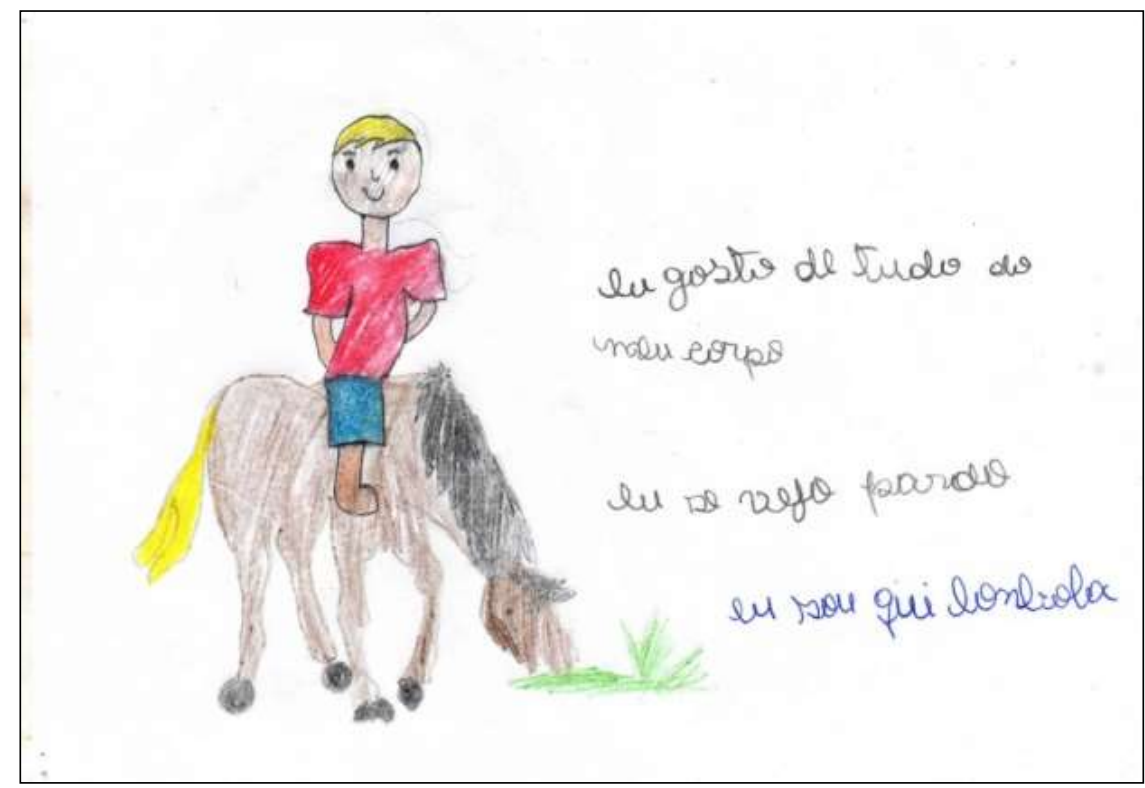

Figura 5 - Desenho de Beija-flor - 11 anos. 


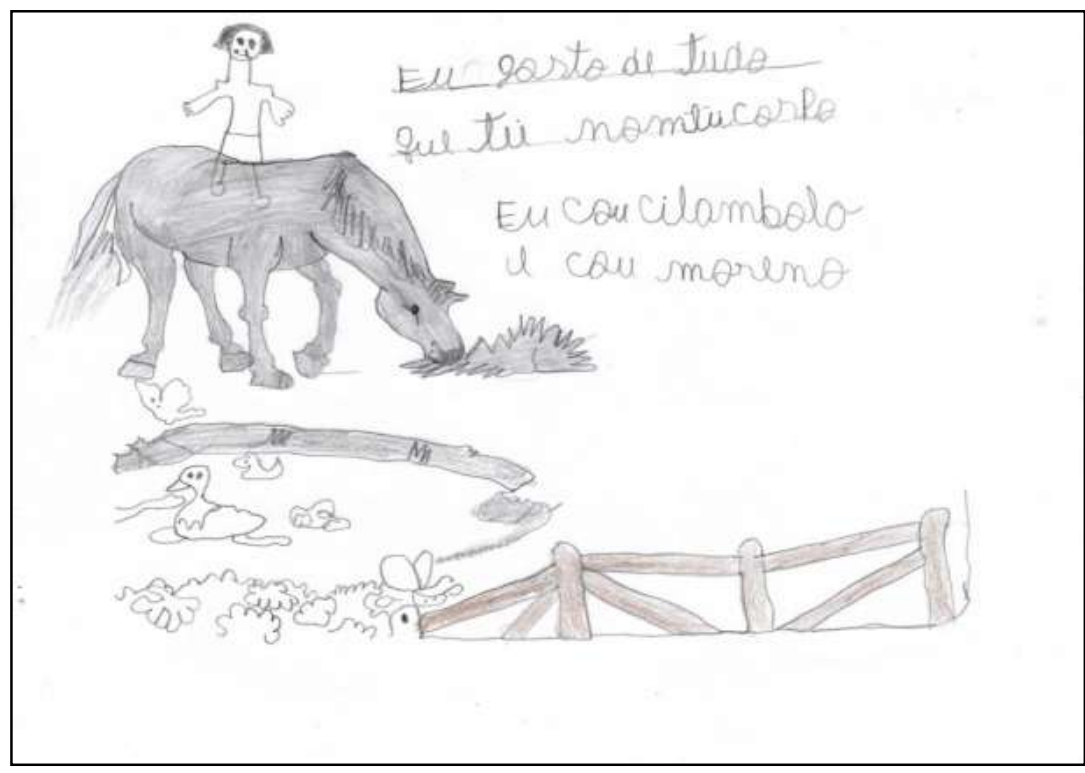

Figura 6 - Desenho de Canário - 10 anos.

Como pode-se observar a relação com a natureza e com os animais do campo foram retratados na produção de Beija-flor e Canário, nas Figuras 5 e 6.

\section{As percepções que as crianças constroem sobre o ser quilombola}

Na tentativa de entender quais as percepções que as crianças pesquisadas têm acerca do ser quilombola, realizamos entrevistas com oito delas, a fim de nos dar subsídios para compreender o que elas pensam e sentem com relação a serem e estarem inseridas em uma comunidade quilombola com tudo que está implicado em ser quilombola na contemporaneidade. Esse exercício analítico foi efetuado dialogando com as proposições de Fazzi (2006), Gobbi e Leite (2009), Gusmão (1999), Honneth (2003).

Conforme demonstramos a seguir, as falas das entrevistas com as crianças e os seus desenhos nos ajudarão nessa compreensão. Direcionando os questionamentos sobre a temática em tela, indagamos sobre o que é ser quilombola para as crianças. As 
respostas obtidas nos encaminharam para pensar que o ser quilombola para elas está estreitamente relacionado com a consciência racial.

$\mathrm{Na}$ argumentação de Beija-flor fica evidenciado que o ser quilombola para ele é “[...] uma pessoa negra, uma pessoa é... uma pessoa... uma pessoa falada bem na comunidade (Beija-flor, entrevista, 2017)". Sobre esse processo de classificação racial, Fazzi (2006) aponta que não é possível interpretar as verdadeiras atitudes raciais das crianças ou a autoestima racial, a não ser que, primeiramente, haja uma investigação de consciência racial, pois é necessário saber se as crianças estão conscientes da raça enquanto uma categoria social.

Quando Beija-flor nos diz que ser quilombola é uma pessoa bem falada na comunidade, nos parece que enquanto grupo, os quilombolas de Nova Esperança teriam atingido a autoestima correspondente ao terceiro estágio de reconhecimento elaborado por Honneth, aquele que corresponde à autoestima interna do grupo, sendo assim, "a estima social se coloca a questão de como se constitui o sistema referencial valorativo no interior do qual se pode medir o "valor" das propriedades características (HONNETH, 2003, p. 187).

O sistema de classificação das crianças refletirá as preferências de suas sociedades, já que elas se apropriarão das categorias que estão disponíveis culturalmente (FAZZI, 2006). É nessa direção apontada pela autora que Canário faz seu discurso alinhado com o de Beija-flor: para ele, o ser quilombola é "negro assim... negro, é bom ser quilombola" (CANÁRIO, entrevista, 2017). Parece-nos que a questão racial é a primeira percepção que as crianças constroem acerca do ser quilombola. Sobre esse aspecto, Fazzi (2006, p. 59) aponta para “[...] a existência de um consenso entre pesquisadores ao contrário da crença popular, de que raça é uma das primeiras dimensões sociais emergentes que a criança observa, e esse padrão de 
desenvolvimento parece ser estável em diversas culturas".

Ainda sobre a visão do ser quilombola construída pelas crianças, a entrevista com Papa Capim nos revela elementos novos para pensar as diversas imagens negativas que foram construídas acerca do negro durante o processo histórico do Brasil. Para ele, ser quilombola é:

[...] é assim, ser quilombola é ser batalhador, é só porque é negro que não tem defeito, mas é batalhador. É a mesma coisa que um homem branco, trabalha, tem que ser muito batalhador ser um quilombola, morar na roça e trabalhar. É assim que nós é. Por isso que eu me considero um quilombola (PAPA CAPIM, entrevista, 2017).

Papa Capim tem uma consciência racial mais elaborada e revela isto em sua fala. Ele busca o predicado positivo "batalhador" para desconstruir uma imagem negativa que historicamente foi elaborada para diminuir os negros. Ele entende que a gradação da pele traz benefícios quando evoca o grupo étnico branco para construir seus argumentos em relação ao ser "batalhador" em referência aos quilombolas. Essa valoração positiva do ser quilombola, apontada por Papa Capim, tem relação com o que afirma Honneth (2003, p. 202): "no interior dos grupos determinados por status, os sujeitos podem se estimar mutuamente como pessoas que, por força da situação social comum, partilham propriedades".

Sobre o processo classificação racial, Fazzi (2006) afirma que, numa sociedade multirracial, as diferenças na cor da pele, forma do cabelo, roupa, discurso, podem se tornar base para processos de classificação. Papa Capim utiliza esses elementos em seu desenho de autorrepresentação, como mostrado na Figura 7.

No desenho ele evidencia o seu pertencimento enquanto criança quilombola, embora não utilize a categoria "negro" para se classificar racialmente. Esse fenômeno é explicado por Fazzi (2006) quando a autora afirma que no Brasil a classificação racial 
do indivíduo é baseada em características fenotípicas e socioeconômicas. Isso implica em um sistema múltiplo de classificação, incluindo diversas categorias.

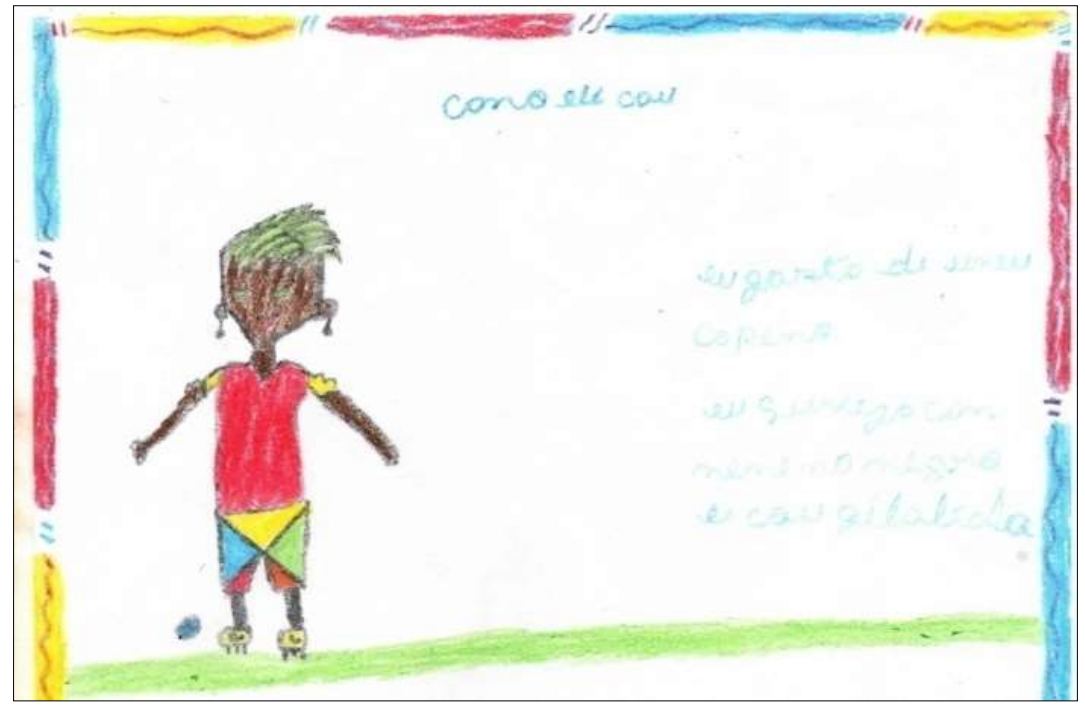

Figura 7 - Desenho de Papa Capim - 13 anos.

Ainda segundo a autora, na linguagem popular o termo preto deve, sempre que possível, ser evitado por estar associado a características negativas. Sobre essa questão Fazzi (2006, p. 72-73) sinaliza que: "O significado social do princípio da gradação da tonalidade da cor da pele, permite que se instaure nas relações sociais entre crianças um processo de negociação social de classificação racial, sendo possível, até um certo ponto, a manipulação de categorias".

Essas características negativas associadas ao negro e, consequentemente, ao ser quilombola (pois é esta a percepção que as crianças inicialmente têm do ser quilombola), afetam o reconhecimento intersubjetivo dos indivíduos, sinalizado por Honneth (2003). Quando Papa Capim, em sua fala, nos diz que ser quilombola é "morar na roça, é trabalhar e ser batalhador", ele está fazendo um esforço para mostrar que ser negro/quilombola é algo diferente do que pregam os discursos difundidos pelos grupos hegemônicos e detentores do capital. 
Os argumentos tecidos até aqui sobre as considerações de Papa Capim têm relação com o que sinaliza Honneth (2003, p. 208-209) no sentido de que

[...] a forma de reconhecimento da estima é organizada segundo estamentos, a experiência da distinção social que lhe corresponde se refere em grande parte somente à identidade coletiva do próprio grupo: as realizações, para cujo valor social o indivíduo pode se ver reconhecido, são ainda tão pouco distintas das propriedades coletivas tipificadas de seu estamento que ele não pode sentir-se, como sujeito individuado, o destinatário da estima, mas somente o grupo em sua totalidade. A auto-relação prática a que uma experiência de reconhecimento desse gênero faz os indivíduos chegar é, por isso, um sentimento de orgulho do grupo ou de honra coletiva; o indivíduo se sabe aí como membro de um grupo social que está em condição de realizações comuns, cujo valor para a sociedade é reconhecido por todos os seus demais membros. Na relação interna de tais grupos, as formas de interação assumem nos casos normais o caráter de relações solidárias, porque todo membro se sabe estimado por todos os outros na mesma medida; pois por "solidariedade" pode se entender, numa primeira aproximação, uma espécie de relação interativa em que os sujeitos tomam interesse reciprocamente por seus modos distintos de vida, já que eles se estimam entre si de maneira simétrica.

Essa relação de estima na estrutura interna do grupo dos quilombolas de Nova Esperança aparece na fala da Papa Capim quando ele busca driblar os estereótipos que historicamente foram e ainda são difundidos sobre os negros e, especialmente, os negros quilombolas. É nesse contexto de negação de direitos que a fala dessa criança tem relevância, pois as experiências individuais de desrespeito são tomadas como experiências coletivas de todo um grupo, motivando assim a exigência coletiva por reconhecimento (HONNETH, 2003). Questionamos as crianças se os professores falavam dos negros e/ou dos quilombolas nas aulas.

Ela falou que os negros antes eram muito, eram escravos. Aí eles viviam presos e usava a capoeira para se defender (COLEIRA, entrevista, 2017).

Que os quilombolas eram sofredores, eram escravos no passado, antigamente sofriam muito (TUCANO, entrevista, 2017).

Que os negros eram escravos antes, foi só isso (CANÁRIO, entrevista, 2017). 
As falas de Coleira, Tucano e Canário demonstram que o currículo praticado na escola tem contribuído para reforçar os estereótipos construídos sobre os negros, quando dá um enfoque histórico para os quilombos, remetendo a um passado de sofrimento e escravidão. Nesse contexto, as crianças tendem a não se verem enquanto quilombolas, pois ser quilombola está associado a aspectos negativos.

Conforme nos assinalam as crianças, a preocupação com a transmissão da cultura e história da comunidade é muito mais das pessoas mais velhas - os netos de Faustino José dos Santos. Esse detalhe contido nas falas dos estudantes vai de encontro com o que evidenciaram os adultos, de que a escola poderia inserir no currículo nas questões da comunidade enquanto quilombolas. Sobre esse assunto, algumas crianças nos afirmam que:

Não, Senhorinha que fala mesmo. Senhorinha que fala quando tem apresentação aí na escola, que é pra falar sobre a família dela... ouvi dona Senhorinha, Florinda, o povo de antes falava sobre os quilombolas, aí eu soube o que era quilombola (Beija-flor, entrevista, 2017).

Um dia que nós estava falando sobre os quilombolas, que nós veio de uma nação dos quilombos, de onde veio as nações dos quilombos. Eu agora eu esqueci o nome do fundador daqui, que era parente das pessoas mais velhas da comunidade (PAPA CAPIM, entrevista, 2017).

Para Beija-flor, que se autodefine como quilombola e tem relação de parentesco com os fundadores da comunidade, o ser quilombola é uma responsabilidade dos mais velhos. Em Nova Esperança, os mais velhos são fundamentais para a preservação/manutenção da cultura da comunidade. Essa transmissão acontece nas relações familiares, envolvendo até três gerações, como sinaliza um deles nos relatando que as primeiras pessoas que falaram sobre os quilombolas para ele foram os "avôs e os meus pais" (CANÁRIO, entrevista, 2017). 


\section{Considerações finais}

A discussão apresentada neste artigo teve a intenção de apontar caminhos metodológicos, no que diz respeito ao uso de desenhos em pesquisas com crianças, entendendo que este recurso pode subsidiar ao pesquisador uma aproximação da realidade construída e vivida pela criança. Buscamos demonstrar a contribuição do uso de desenhos como recurso metodológico para a produção dos dados e que possibilita a aproximação entre o pesquisador e as múltiplas experiências individuais e coletivas das crianças, compreendidas como sujeitos culturais e históricos e que, portanto, dão significados e significam aquilo que desenham. Os desenhos apresentados no decorrer do texto permitiram captar as concepções que as crianças da comunidade quilombola de Nova Esperança constroem acerca do ser quilombola e de como elas percebem a escola e as práticas pedagógicas nela desenvolvidas.

\section{Referências}

ARAÚJO, C. C. M.; LACERDA, C. B. F. Esferas de atividade simbólica e a construção de conhecimento pela criança surda. Rev. Bras. Educ. Especial, Marília, v. 14, n. 3, p. 427-446, 2008. Disponível em: http://www.scielo.br/pdf/rbee/v14n3/v14n3a07.pdf. Acesso em: 16 jan. 2019.

DERDYK, E. Formas de pensar o desenho: desenvolvimento do grafismo infantil. São Paulo: Scipione, 1989.

FAZZI, R. C. O drama racial de crianças brasileiras: sociologia entre pares e preconceito. 1. ed. Belo Horizonte: Autêntica, 2006.

FERREIRA, S. Imaginação e linguagem no desenho da criança. 2. ed. Campinas: Papirus, 2001.

GOBBI, M. Desenho infantil e oralidade: instrumentos para pesquisas com crianças pequenas. In: FARIA, A. L. G.; DEMARTINI, Z. B. F.; PRADO, P. D. (org.). Por uma cultura da infância: metodologias de pesquisa com crianças. 2. ed. Campinas: Autores Associados, 2005. p. 67-92. 
GOBBI, M.; LEITE, M. I. O desenho da criança pequena: distintas abordagens na produção acadêmica em diálogo com a educação. 2009. Disponível em: http://www.ced.ufsc.br/ nee0a6/ LEITE.pdf. Acesso em: 05 jan. 2019.

GUSMÃO, N. M. M. Linguagem, cultura e alteridade: imagens do outro. Cadernos de Pesquisa, São Paulo, n. 107, p. 41-78, 1999. Disponível em:

http://www.scielo.br/pdf/cp/n107/n107a02.pdf. Acesso em: 05 jan. 2019.

HONNETH, A. Luta por reconhecimento: a gramática moral dos conflitos sociais. Tradução: Luis Repa. São Paulo: Editora 34, 2003.

LEITE, A. L. Por que o menino tá fora da roda?. Centro Educacional de Desenvolvimento Integrado. 2004. Disponível em: http://www.cedi.g12. br/article.php3?id_article=1360. Acesso em: 05 jan. 2019.

NATIVIDADE, M. R.; COUTINHO, M. C.; ZANELLA, A. V. Desenho na pesquisa com crianças: análise na perspectiva histórico-cultural. Contextos Clínicos, São Leopoldo, v. 1, n. 1, p. 9-18, 2008. Disponível em:

http://pepsic.bvsalud.org/pdf/cclin/v1n1/v1n1a02.pdf. Acesso em: 05 jan. 2019.

PEDRINI, A.; COSTA, E. A.; GHILARDI, N. Percepção ambiental de crianças e préadolescentes em vulnerabilidade social para projetos de Educação Ambiental. Ciência \& Educação, Bauru, v. 16, n. 1, p. 163-179, 2010. Disponível em: http://www.scielo.br/pdf/ciedu/v16n1/v16n1a10.pdf. Acesso em: 05 jan. 2019.

PEREIRA, L. T. K. O desenho infantil e a construção da significação: um estudo de caso. 2005. Disponível em: http://atividadeparaeducacaoespecial.com/wpcontent/uploads/2014/11/lais-krucken-pereira.pdf. Acesso em: 05 jan. 2019.

PIRES, F. Ser adulto e investigar crianças: explorando possibilidades metodológicas na pesquisa antropológica. Revista de Antropologia, São Paulo, v. 50, n. 1, p. 225-270, 2007. Disponível em: http://www.scielo.br/pdf/ra/v50n1/a06v50n1.pdf. Acesso em: 05 jan. 2016.

Enviado em: 30/05/2019

Aprovado em: 28/12/2019 